\title{
Ceriporia lacerata (Phanerochaetaceae, Basidiomycota): A new record from Pakistan
}

\author{
Wahab $\mathrm{A}^{1}$, Ryvarden $\mathrm{L}^{2}$, Pfister $\mathrm{DH}^{3}$, Sirajuddin ${ }^{1}$ and Khalid $\mathrm{AN}^{4}$ \\ ${ }^{1}$ Department of Botany, University of Peshawar, KP, Pakistan. \\ ${ }^{2}$ Institute of Biological Sciences, University of Oslo, Norway. \\ ${ }^{3}$ Department of Organismic and Evolutionary Biology, Harvard University, 22 Divinity Avenue,Cambridge, MA 02138 \\ ${ }^{4}$ Department of Botany, University of the Punjab, New Campus, 54590, Lahore, Pakistan.
}

Wahab A, Ryvarden L, Pfister DH, Sirajuddin, Khalid AN 2018 - Ceriporia lacerata (Phanerochaetaceae, Basidiomycota): A new record from Pakistan. Asian Journal of Mycology 1(1), 9-14, Doi 10.5943/ajom/1/1/2

\begin{abstract}
A Ceriporia species was collected during a field survey in Malakand district, Khyber Pakhtunkhwa, Pakistan. Based on morphological characteristics and molecular data from internal transcribed spacer rDNA, the species was identified as Ceriporia lacerata. A literature review confirms this to be the first record of the species from Pakistan.
\end{abstract}

Key words - basidiomycetes - polypore - taxonomy - molecular data

\section{Introduction}

Ceriporia Donk (1933), is a genus belonging to the Phanerochaetaceae, Polyporales, with Polyporus Ceriporia viridans Berk. \& Broome ( $\equiv$ C. virdans (Berk. \& Broome) Donk) as type species. The species in this genus have an annual growth habit, cause a white rot, produce resupinate basidiocarps with variable colours of their poroid hymenial surface, a monomitic hyphal structure with simple septa on generative hyphae, hyaline, thin-walled and usually cylindrical to oblong-ellipsoid and inamyloid basidiospores (Gilbertson \& Ryvarden 1986, Ryvarden 1991, Ryvarden \& Gilbertson 1993, Núñez \& Ryvarden 2001). However, a few species have also been placed in the genus that have a dimitic hyphal structure, generative hyphae with clamp connections and cystidia. This is because of their similar growth habit and basidiospore characteristics (Buchanan \& Ryvarden 1988, Pieri \& Rivoire 1997, Ryvarden \& Iturriaga 2003, Aime et al. 2007). Microscopical examinations are the basis of most taxonomical studies of Ceriporia (Gilbertson \& Ryvarden 1986, Ryvarden \& Iturriaga 2003). Only a few phylogenetic studies based on molecular markers have been performed as a supplement to classical taxonomical studies. The genus was at first considered monophyletic (Kim \& Jung 1999), but it was recently shown that it is polyphyletic and that the presence or absence of cystidia is not considered a phylogenetic character in delimiting its species. Ceriporia species have a wide distribution. It currently includes almost 40 species (Jia et al. 2014), of which 18 have been recorded from the Neotropics (Ryvarden \& Iturriaga 2003, Aime et al. 2007, Mata \& Ryvarden 2010, Gomes-Silva et al. 2012). In Pakistan, three Ceriporia species have been reported i,e., C. ferruginicinata (Murr.) Ryv., C. leptoderma (Berk. and Br.) Ryv., and C. xylostromatoides (Berk.) Ryv. During our studies on the diversity of polyporoid fungi in KhyberPakhtunkhwa Forests, an unreported Ceriporia specie was found. The basidiomata were 
identified using morphological characters and sequence analyses of the internal transcribed spacer (ITS) rDNA region supported the identification. A detailed description of the species and a key to the Pakistani Ceriporia species is provided below.)

\section{Materials \& Methods}

\section{Collections}

Collection of the basidiocarps was based on regular field visits to the forests of the Malakand district, during 2015. Important macroscopic features were noted from fresh specimens which were dried using a fan heater with temperature adjusted to $40^{\circ} \mathrm{C}$.

\section{Macro-Microscopic observation}

Macro and microscopic basidiocarp features were noted. Measurements and drawings were made from slide preparations mounted in a drop of lactic acid, Melzer's reagent or 5\% KOH and were observed (Largent et al. 1977). Microscopic features were measured using calibrated Piximetre software connected to a B-350 Optika compound microscope through a Scope Image (H9D) camera and visualized on a computer screen.

Twenty basidiospores, basidia, and cystidia were measured and recordedas follows: $Q=$ the length/width ratio of a single spore; $\mathrm{Qe}=$ average length/width ratio of all spores; $\mathrm{Me}=$ average $\mathrm{L} \times \mathrm{W}$ of all spores measured.

\section{DNA extraction, amplification, sequencing, and molecular phylogenetic analysis}

\section{Molecular Characterization}

About $50 \mathrm{mg}$ samples were ground into fine powder using liquid nitrogen. DNA was extracted according to Gardes \& Bruns (1996). The universal primer pair ITS1F and ITS 4 (White et al. 1990, Gardes \& Bruns 1993) was used to amplify the rDNA ITS (ITS1F+5.8s+ITS4) region in $50 \mu \mathrm{L}$ reaction volumes following Gardes \& Bruns (1993). The PCR products were sequenced by Beijing Genomic Institute (Hong Kong). BLAST analysis was performed using the National Center for Biotechnology Information (USA) database, and closely matching sequences were downloaded for further phylogenetic analysis. Sequences were aligned using MEGA 7 software (Kumar et al. 2016). Sequences are deposited in GenBank.

The evolutionary history was inferred by using the maximum Likelihood method based on the Tamura 3-parameter model. The percentage of trees in which the associated taxa clustered together is shown next to the branches. Initial tree(s) for the heuristic search were obtained automatically by applying Neighbor-Join and BioNJ algorithms to a matrix of pairwise distances estimated using the Maximum Composite Likelihood (MCL) approach, and then selecting the topology with superior log likelihood value. A discrete Gamma distribution was used to model evolutionary rate differences among sites $(5$ categories $(+G$, parameter $=1.0194)$ ). The tree is drawn to scale, with branch lengths measured in the number of substitutions per site. The analysis involved 36 nucleotide sequences. All positions containing gaps and missing data were eliminated. There were a total of 494 positions in the final dataset. Evolutionary analyses were conducted in MEGA7. The local collection is shown as

\section{Results}

The ITSIF and ITS4 regions amplified consisted of 640bp. The initial BLAST comparison of the Pakistan sequences showed 99\% identity and 95\% query cover with Ceriporia lacerata N. Maek., Suhara \& R. Kondo, (KP135024.1, KU194322.1, KU194321.1, KF850375.1). Identical sequences were retrieved from GenBank and were aligned through online tool MUSCLE https://blast.ncbi.nlm.nih.gov/Blast.cgi. The MEGA7 maximum likelihood analysis clustered our 
Pakistan sequence with the $C$. lacerata sequences in a separate clade with a strong bootstrap value of $99 \%$.

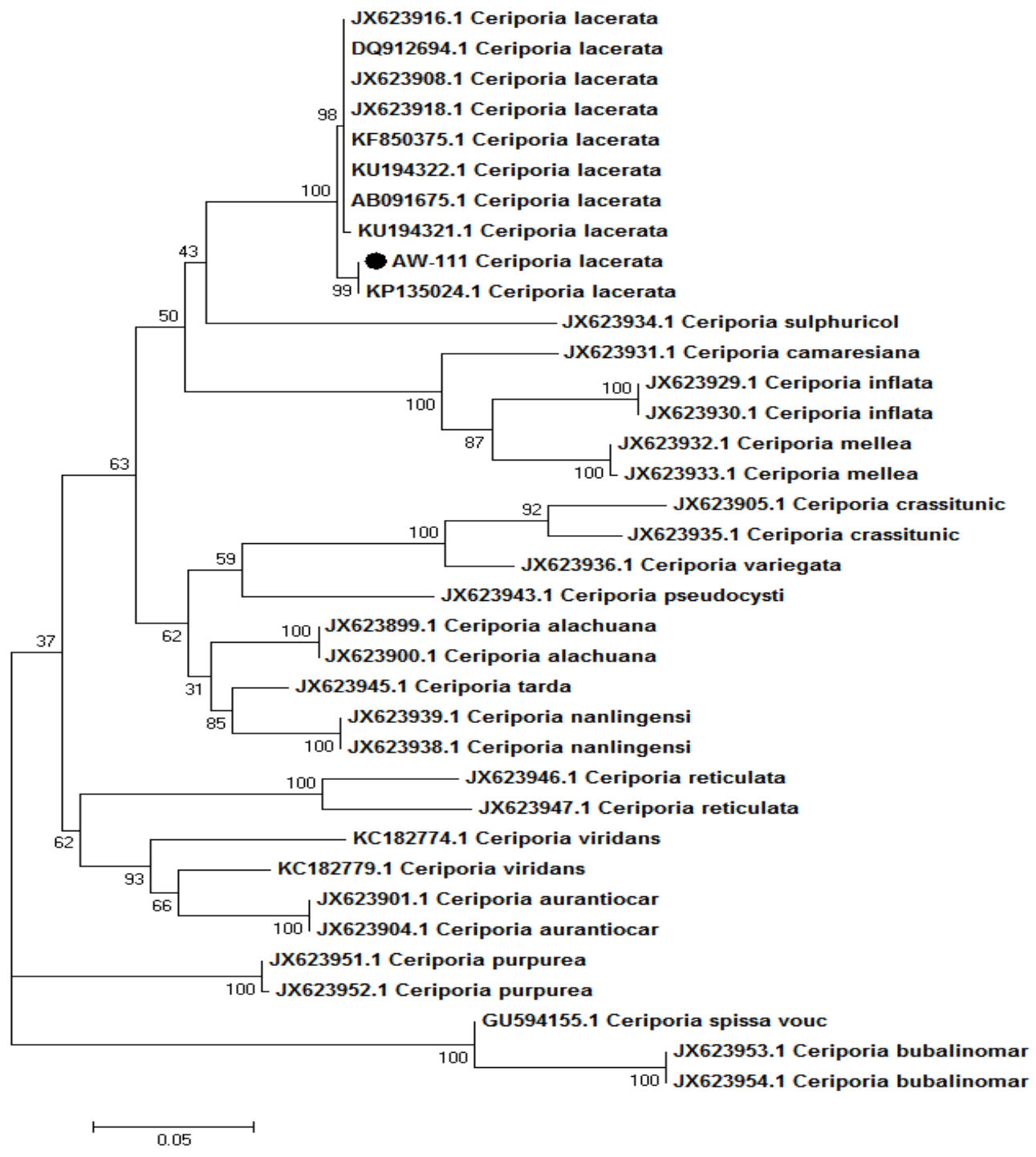

Fig. 1 - Phylogram obtained from ITS region of nrDNA. The phylogenetic relationship of Ceriporia lacerta was inferred from nrITS sequences using Maximum Likelihood method. Bootstrap values more than 50\% are present above branches. Aw-111 Ceriporia lacerata sequences are indicated by $\bullet$.

\section{Taxonomy}

Ceriporia lacerata N. Maek., Suhara \& R. Kondo, Mycotaxon 86: 342. 2003.

Fig. 2

Basidiocarp resupinate, effused, confluent, soft when fresh, then fragile, firmly attached to the substrate; hymenophore poroid, pore surface white, buff to ochreous; dissepiments entire to lacerate; pores angular, 2-5 per mm; margin white. Hyphal system monomitic; contextual hyphae $3.4-5.8 \mu \mathrm{m}$ in diameter, smooth, thin to slightly thick-walled, simple-septate; tramal hyphae 2.9$4.7 \mu \mathrm{m}$ in diam, smooth, thin to slightly thick-walled, simple-septate, cystidia lacking; basidia clavate, (12.4) 12.6-14.4 (14.5) $\times(3.9) 4.3-5.3(5.8) \mu \mathrm{m} \mathrm{Q}=(2.2) 2.7-3.1$ (3.5); $\mathrm{N}=8 \mathrm{Me}=$ $13.4 \times 4.8 \mu \mathrm{m} ; \mathrm{Qe}=2.8$, with 2-4 sterigmata; basidiospores oblong-ellipsoid to ellipsoid, (3.4) 3.7$4.8(5.1) \times(2.5) 2.7-3.2(3.4) \mu \mathrm{m} \mathrm{Q}=(1.2) 1.3-1.7$ (1.9); $\mathrm{N}=20 ; \mathrm{Me}=4.4 \times 3 \mu \mathrm{m} ; \mathrm{Qe}=1.5$, smooth, thin-walled.

Habitat - On stem bark of Albizia lebbeck 
Specimens examined - PAKISTAN, Khyber Pakhtunkhwa, Malakand, Totakan, $570 \mathrm{~m}$ asl, on bark of Albezzia lebbek, 08. 8 2015, A. Wahab (AW-111).

Type of Rot - white rot

Remarks - Ceriporia lacerata is characterised by having effused and resupinate fruiting body with monomitic, simple septate hyphal system.
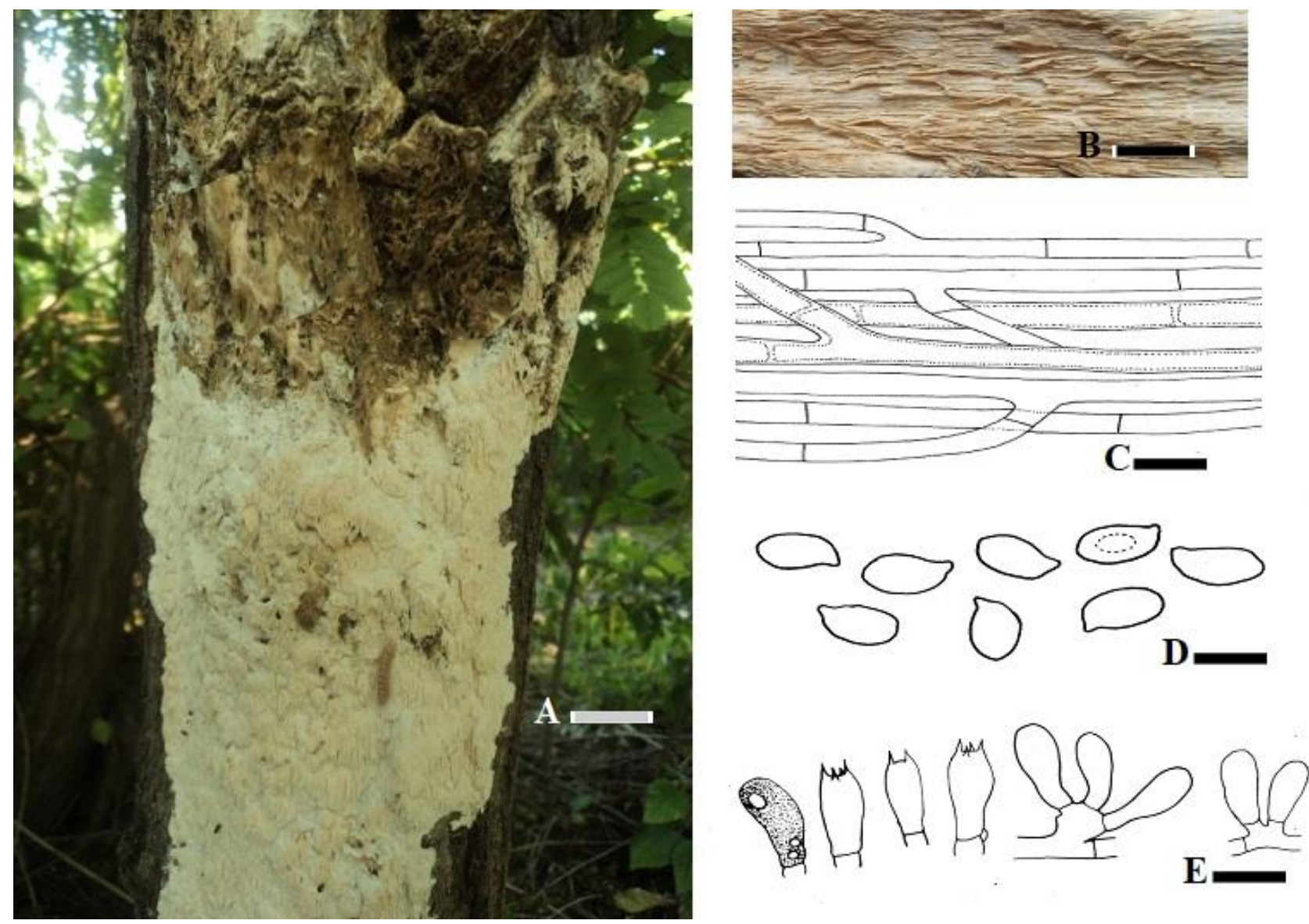

Fig. 2 - Ceriporia lacerata. A Basidiocarp. B Pores. C Generative hyphae. D Basidiospores. E Basidia. Scale bar $A=25 \mathrm{~mm}, B=1.1 \mathrm{~mm}, C=2.7 \mu \mathrm{m}, \mathrm{D}=2.1 \mu \mathrm{m}, \mathrm{E}=2 \mu \mathrm{m}$

\section{Discussion}

Previously three Ceriporia species were reported from Pakistan (Ahmad \& Ahmad 1982). During our study on diversity of polyporoid fungi in KP Forests, an unreported Ceriporia lacerata was found. Ceriporia lacerata was first described from Japan in 2003 (Suhara et al. 2003). It was found on living and dead trunks, branches, rotten stumps of both angiosperm and gymnosperm wood commonly in temperate to tropical ecosystems (Suhara et al. 2003). Our study also confirms that Albezia lebbek is a host plant for C. lacerata. Morphologically, C. lacerata is similar to $C$. alachuana (Murrill) Hallenb. and C. ferruginicincta (Murrill) Ryvarden in having a whitish to ochraceous pore surface and oblong to ellipsoid basidiospores. However, the other two species differ in having pores with entire dissepiments (3-8 per $\mathrm{mm}$ in $C$. alachuana and 6-8 per $\mathrm{mm}$ in $C$. ferruginicincta) according to Suhara et al. (2003), contrasting with the entire to lacerate dissepiments (2-5 per $\mathrm{mm}$ ) of $C$. lacerata.

The ITS rDNA phylogenetic trees had similar topologies in which Ceriporia lacerata formind a clade distinct from that of the other Ceriporia species (Fig. 1). On the other hand, all the analyzed Ceriporia species were monophyletic in $18 \mathrm{~S}$ rDNA tree, as previously suggested by $\mathrm{Wu}$ et al. (2010), with C. spissa (Schwein.) Rajchenb. sister to C. lacerata. The phylogenetic conflict represented here is probably the result of limited taxon sampling. More molecular data derived from other species are needed for the clear elucidation. 
Pakistani collection of Ceriporia lacerata 111 showed polymorphism at six different sites of C. lacerata (KU194321 JX623918 JX623908 JX623916 DQ912694 KF850375 KU194322 AB091675) given in Table 1.

However, information regarding this species is still limited and the pharmacological abilities of this species should be investigated further.

Table 1 Polymorphism at six different sites with reported species from Pakistan.

\begin{tabular}{|l|l|l|l|l|l|l|l|}
\hline & Species & Country & 35 & 44 & 109 & 120 & 518 \\
\hline$\bullet$ AW-111 & C. lacerata & Pakistan & C & A & A & C & G \\
\hline KP135024 & C. lacerata & USA & T & G & T & T & A \\
\hline AB091675 & C. lacerata & JAPAN & T & G & T & T & A \\
\hline KU194321 & C. lacerata & China & T & G & T & T & A \\
\hline JX623918 & C. lacerata & China & T & G & T & T & A \\
\hline JX623908 & C. lacerata & China & T & G & T & T & A \\
\hline JX623916 & C. lacerata & China & T & G & T & T & A \\
\hline DQ912694 & C. lacerata & Korea & T & G & T & T & A \\
\hline KF850375 & C. lacerata & China & T & G & T & T & A \\
\hline KU194322 & C. lacerata & China & T & G & T & T & A \\
\hline
\end{tabular}

\section{References}

Ahmad S, Ahmad N. 1982 - Contribution to the fungi of Pakistan. XX. Bull. Mycol. 2: 79-86.

Aime L, Ryvarden L, Henkel TW. 2007 - Studies in Neotropical polypores 22. Additional new and rare species from Guyana. Synop Fungorum 23:15-31.

Buchanan PK, Ryvarden L. 1988 - Type studies in the Polyporaceae 18. Species described by G.H. Cunningham. Mycotaxon 31:1-38.

Donk MA. 1933 - Revision de Niederlandischen Homobasidiomycetes.Aphyllophoraceae 2. Medd Bot Mus Herb Rijhs Universit Utrecht 9:1-278.

Gardes M, Bruns TD. 1993 - ITS primers with enhanced specificity for basidiomycetes application to the identification of mycorrhizae and rusts. Mol. Ecol 2:113-118.

Gardes M, Bruns TD. 1996 - ITS-RFLP matching for identification of fungi. In: Clapp, J. P., ed. Methods in molecular biology, Vol. 50. Species diagnostics protocols: PCR and other nucleic acid methods. Totowa, NJ: Humana Press Inc.; 177-186.

Gilbertson RL, Ryvarden L. 1986 - North American polypores. Fungiflora, Oslo.

Gomes-Silva AC, Ryvarden L, Gibertoni TB. 2012 - Resupinate poroid fungi from tropical rain forests in Brazil: two new species and new records. Mycol Prog 11:879-885.

Jia BS, Zhou LW, Cui Bk, Rivoire B, Dai YC. 2014 - Taxonomy and phylogeny of Ceriporia (Polyporales, Basidiomycota) with an emphasis of Chinese collections. Mycological Progress 13: 81-93.

Kim SY, Jung HS. 1999 - Molecular taxonomy of Ceriporia. Mycotaxon 70:237-246.

Kumar S, Stecher G, Tamura K. 2016 - MEGA7: Molecular Evolutionary Genetics Analysis Version 7.0 for Bigger Datasets. Mol. Biol. Evol. 33(7):1870-1874.

Largent DL, Johnson D, Watling R. 1977 - How to Identify Mushrooms to genus III: Microscopic Features. Mad River Press, Inc. Eureka, USA.

Mata M, Ryvarden L. 2010 - Studies in Neotropical polypores 27. More new and interesting species from Costa Rica. Synop Fungorum 27:59-72.

Núñez M, Ryvarden L. 2001 - East Asian Polypores. Vol. 2. Polyporaceae s. lato. Synopsis Fungorum 14: 119-522.

Pieri M, Rivoire B. 1997 - A propos du genre Ceriporia Donk (Aphyllophoromycetideæ). Bull Soc Mycol Fr 113:193-250. 
Ryvarden L. 1991 - Genera of polypores: Nomenclature and taxonomy. Synopsis Fungorum 5:1363.

Ryvarden L, Gilbertson RL. 1993 - European polypores. Synopsis Fungorum 6:1-387.

Ryvarden L, Iturriaga T. 2003 - Studies in neotropical polypores 10.New polypores from Venezuela. Mycologia 95:1066-1077.

Suhara H, Maekawa N, Kaneko S, Hattori T et al. 2003 - A new species, Ceriporia lacerata, isolated from white-rotted wood. Mycotaxon 86:335-347.

White TJ, Bruns TD, Lee S, Taylor J. 1990 - Amplification and direct sequencing of fungal ribosomal RNA genes for phylogenetics. In: Innis MA, Gelfand DH, Sninsky JJ, White TJ (eds) PCR protocols, a guide to methods and applications. Academic, San Diego, pp 315322.

Wu SH, Nilsson HR, Chen CT, Yu SY, Hallenberg N. 2010 - The white rotting genus Phanerochaete is polyphyletic and distributed throughout the phleboid clade of the Polyporales (Basidiomycota). Fungal Divers 42:107-118. 